\title{
Chronic subdural haematoma preceded by persistent traumatic subdural fluid collection
}

\author{
KIKUO OHNO,* RYUTA SUZUKI,* HIROYUKI MASAOKA,* \\ YOSHIHARU MATSUSHIMA, * YUTAKA INABA,* SEIJI MONMA† \\ From the Department of Neurosurgery, Tokyo Medical and Dental University, ${ }^{*}$ Tokyo, and the Department \\ of Neurosurgery, Fujiyoshida City Hospital, $\uparrow$ Yamanashi, Japan
}

SUMMARY The role of traumatic subdural fluid collections in the development of chronic subdural $\overrightarrow{\vec{\omega}}$ haematomas was studied in 43 of 715 patients who underwent a CT scan because of a recent head $\frac{\rho}{3}$ injury. Twenty of the 43 patients subsequently developed a chronic subdural haematoma, and this occurred especially in the aged. Nearly $50 \%$ of patients with asymptomatic or minimally sympto-ir matic subdural fluid collection may develop a chronic subdural haematoma.

Chronic subdural haematoma was initially noted by Virchow in 1857 and thought to be due to "pachymeningitis hemorrhagica interna". ${ }^{1}$ Since CT became available, chronic subdural haematoma has been studied neuroradiologically, and its development after head injury has also been investigated on serial CT scans. ${ }^{2-9}$ In 1979 , Yamada et $a l^{10}$ first reported three cases in which a chronic subdural haematoma developed following a traumatic subdural hygroma (posttraumatic low-density subdural fluid collection) but it is unclear how often this occurs. We therefore have reviewed 43 consecutive patients who had a traumatic subdural fluid collection.

\section{Cases and methods}

We studied the patients who, between August 1980 and March 1985, were found to have a traumatic subdural fluid collection on a CT scan taken after a head injury. A chronic subdural haematoma was defined as a subdural fluid blood collection encapsulated between outer and inner membranes. In the present study, the patients were diagnosed as having chronic subdural haematoma at the time of their operation or, alternatively, when a CT scan more than 2 weeks after the head injury showed hyper- or iso-dense areas

Address for reprint requests: Kikuo Ohno, M.D., Department of Neurosurgery, Tokyo Medical and Dental University, 1-5-45 Yushima, Bunkyo-ku, Tokyo 113, Japan.

Received 13 March 1987 and in revised form 16 June 1987. Accepted 19 June 1987 in an area previously hypodense on CT. During the period, 30 other patients with a chronic subdural ho matoma were diagnosed on their first CT scan, with no ey dence of previous subdural fluid collection; of these patients, only six had no history of head injury.

\section{Results}

A traumatic subdural fluid collection was found in $43 \%$ (6\%) of 715 patients who underwent CT within 6 days of a head injury. Twenty four of the 43 patients were more than 65 years old (an incidence of $30 \%$ in 79 patients over 65 years old), whereas 19 patients were $\overline{0}$ 64 years old or less (an incidence of $3 \%$ ). A chronic $\stackrel{0}{\not}$ subdural haematoma developed in $20(47 \%)$ of the $43 \stackrel{\square}{\perp}$ patients; in the other 23 patients there was spontane- $\overrightarrow{\vec{\sigma}}$ ous resolution of the collection. Thirteen of the 243 patients over 65 years old developed a chronic subdural haematoma, as did seven of the 19 younger patients.

The 20 patients in whom the subdural fluid col- $\frac{5}{0}$ lection progressed to a chronic subdural haematoma $:$ included 18 males and two females. Their average age 3 . was 65 years, ranging from 27 to 84 . The cause of head injury was a traffic accident in 13 cases. Four- 3 teen patients lost consciousness for 6 hours or less and $\mathrm{O}$ only two had no loss of consciousness. Four patients had frontal lobe contusions and two had single intra- $\frac{}{2}$ cerebral haematomas. Most patients sought treatment investigation early because of the severity of the $\widetilde{N}$ injury and the medico-legal aspects of the traffic acci- $N$ 
dent. Traumatic subdural fluid collection was detected by CT within 10 days after the injury in 17 patients (average 3 days); in three patients frontal hypodense areas developed later. Bilateral collections were found in 15 patients. Nineteen patients who were asymptomatic were followed by $\mathrm{CT}$, usually weekly; one patient had external drainage because of prolonged impairment of consciousness. The subdural fluid collections which later developed into a chronic subdural haematoma had initial density measurements of $27.1 \pm 6.7$ (Hounsfield units (HU), mean $\pm S D, n=23$ ), while the CSF in the ventricles measured $14.3 \pm 3 \cdot 0$. There was a statistically significant difference between measure values in hypodense areas and the ventricles (paired $t$ test, $\mathrm{p}<$ 0.01 ). Three hypodense areas in two patients were not measured.

The chronic subdural haematomas developed between 18 and 126 days after the head injury (average interval $68 \pm 34$ days) (fig). Twelve of the 20 patients showed an increase in the size of the extracerebral lesion; these also suffered from signs and symptoms such as headache, vomiting and gait disturbance and, therefore, were operated on. In seven of the remaining eight patients there was spontaneous resolution of the haematoma. One patient died of an accident during the period of observation. In nine of 15 patients with bilateral frontal hypodense areas, the
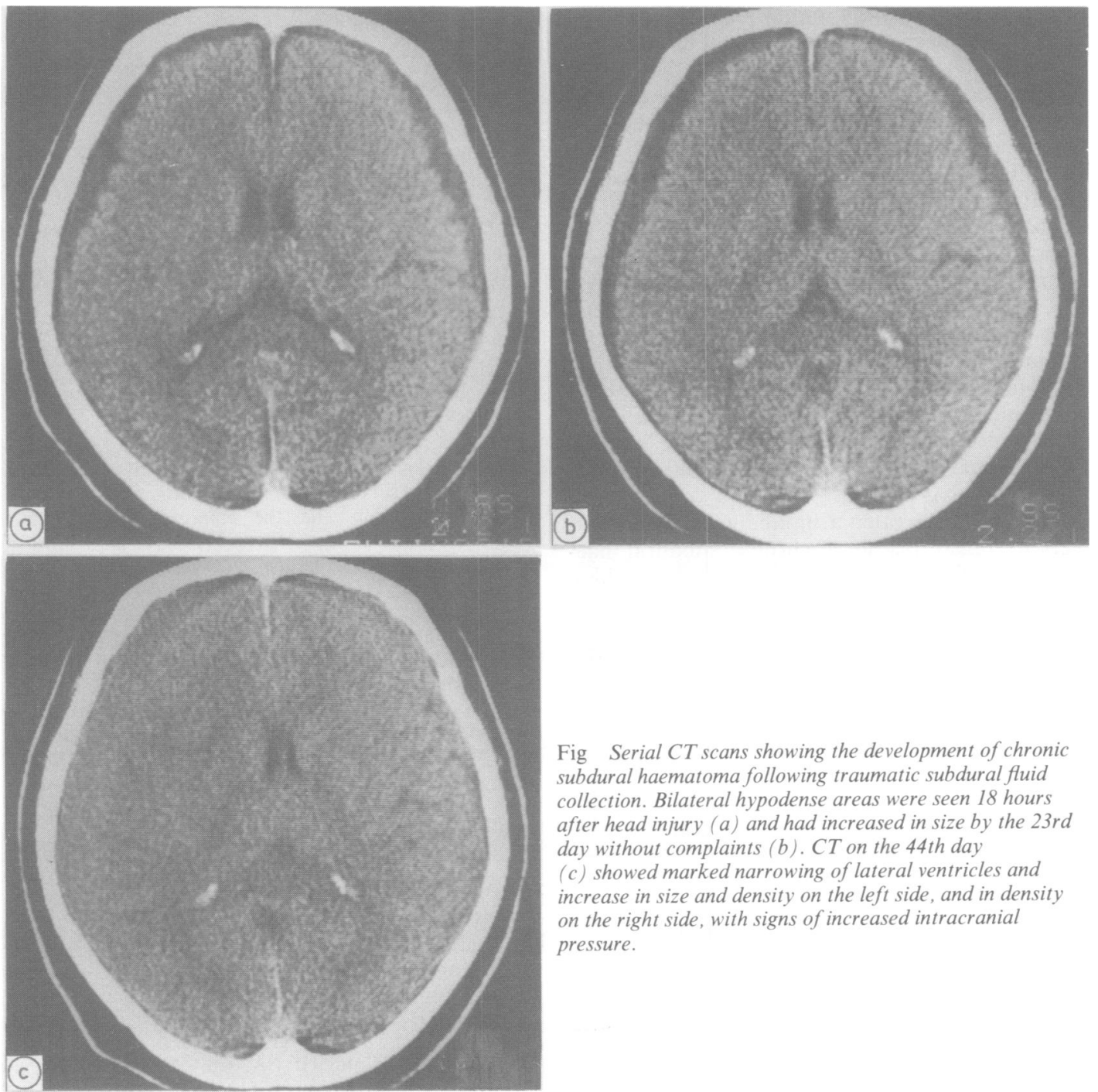

Fig Serial CT scans showing the development of chronic subdural haematoma following traumatic subdural fluid collection. Bilateral hypodense areas were seen 18 hours after head injury (a) and had increased in size by the 23rd day without complaints (b). CT on the 44th day (c) showed marked narrowing of lateral ventricles and increase in size and density on the left side, and in density on the right side, with signs of increased intracranial pressure. 
hypodense area disappeared on one side but a chronic subdural haematoma developed on the side with the persisting subdural fluid collection. The other six developed chronic subdural haematomas on both sides, in two at different times on the two sides. Five patients with unilateral subdural fluid collection developed an increased density collection on the same side.

\section{Discussion}

Frontal extracerebral hypodense areas seen on CT scans after the head injury are usually regarded as a traumatic subdural fluid collection if they subsequently change in size or show a higher CT density than CSF. Such traumatic subdural fluid collections are reported to occur in $4 \%$ to $6.6 \%$ of head-injured patients. $^{811}$ They developed in $6 \%$ of the present series also and were more common in older patients. The higher CT density indicated that the subdural fluid was not merely CSF but CSF mixed with varying amounts of blood. ${ }^{12} 13$ Though the mechanism of subdural fluid collection is not clearly understood, the fluid may flow from the subarachnoid space via arachnoid tears, probably at the sites of contusion or bridging veins, and collect by "flap valve action". 611-13 Traumatic subdural fluid collections tend to occur bilaterally at first. If they persist for a long time, a chronic subdural haematoma may develop on either side. The change in the subdural fluid results from haemorrhage from the neomembrane formed under the dura but it remains unknown what causes the haemorrhage and when the inner membrane is formed.

Estimates of how often a traumatic subdural fluid collection transforms to a chronic subdural haematoma vary from $0 \%$ to $58 \%^{2368111314}$ (table). The reason for the varying incidence is not clear. In the series of Stone et al, ${ }^{13}$ not all patients had CT examinations and surgery was usually done early.

Table Incidence of transformation of traumatic subdural fluid collection to chronic subdural haematoma

\begin{tabular}{|c|c|c|}
\hline Author & $\begin{array}{l}\text { No of patients } \\
\text { with TSDC }\end{array}$ & $\begin{array}{l}\text { No of patients who } \\
\text { developed CSDH } \\
\text { following TSDC }\end{array}$ \\
\hline 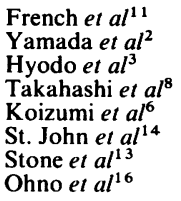 & $\begin{array}{l}13(0)^{*} \\
24(9) \\
24(?) \\
26(13) \\
38(20) \\
25(11) \\
80(?) \\
43(27)\end{array}$ & $\begin{aligned} 0 & \\
12 & (7)^{*} \\
2 & \\
15 & (7) \\
4 & (4) \\
1 & (1) \\
0 & \\
20 & (15)\end{aligned}$ \\
\hline
\end{tabular}

Abbreviations: TSDC: traumatic subdural fluid collection; $\mathrm{CSDH}$ : chronic subdural haematoma.

*No of patients more than 60 years old in parentheses.
Chronic subdural haematoma may produce little or no symptoms; spontaneous resolution may occur ${ }^{15}$ as in seven of 20 patients in the present study. Such patients may be overlooked if there is no intensive examination by CT. The high incidence in the Japanese reports therefore may be attributed to the practice of careful, frequent follow-up by serial CT.

Our study suggests that a chronic subdural haematoma usually develops as a consequence of a traumatic subdural fluid collection in a head-injured patient. ${ }^{16}$ Nearly $50 \%$ of all patients with a traumatic subdural fluid collection may later develop a chronic subdural haematoma and this is more common in older persons.

\section{References}

1 Virchow R. Das Hämatom der Dura mater. Verh Phys Med Ges Würzburg 1857;7:134-42.

2 Yamada $\mathrm{H}$, Watanabe $\mathrm{T}$, Murata $\mathrm{S}$, et al. Developmental process of chronic subdural collections of fluid based on CT scan findings. Surg Neurol 1980;13:441-8.

3 Hyodo A, Nose T, Enomoto T, Maki Y. Chronic subdural hematoma - Changed its density from low to high on follow-up CT. Neurol Surg (Tokyo) 1980;8 649-53.

4 Miyazaki S, Ohmori H, Kanazawa Y, Munekata $\mathrm{K}$, Fukushima H, Kamata $K$. The pathogenesis of chronic subdural hematoma-Sequential study witho computerized tomography. Neurol Med Chir 1980;20:875-81.

5 Fujioka M, Matsukado Y, Kaku M, Sakurama N, Nonaka N, Miura G. CT analysis of 100 cases withō chronic subdural hematoma with respect to clinica? manifestation and the enlarging process of the hematoma. Neurol Med Chir 1981;21:1153-60.

6 Koizumi H, Fukamachi A, Wakao T, Tasaki T, Nagaseki Y, Yanai Y. Traumatic subdural hygromas in adults: on the possibility of development of chronic subdural hematoma. Neurol Med Chir 1981;21: 397-406.

7 Naito T, Maegawa M, Morimoto T, et al. Clinical and computerized tomographic studies of chronic subdural hematomas. Neurol Med Chir 1981;21:961-8.

8 Takahashi Y, Sato H, Inoue Y, Takeda S, Ohkawara S. CT findings and the evaluation of chronic subdural hematoma (Part 1)-Forecast of chronic subdural hematoma. Neurol Med Chir 1981;21:485-90.

9 Takahashi Y, Mikami J, Sato H, et al. Analysis of chronic subdural hematoma based on CT (Part 2). Symptoms and CT findings. Neurol Med Chir 1982;22:395-401.

10 Yamada H, Nihei H, Watanabe T, Shibui S, Murata S. Chronic subdural hematoma occurring consequently to the post-traumatic subdural hygroma-On the pathogenesis of the chronic subdural hematoma. No to Shinkei 1979;31:115-21.

11 French BN, Cobb III CA, Corkill G, Youmans JR. Delayed evolution of posttraumatic subdural 
hygroma. Surg Neurol 1978;9:145-8.

12 DaCosta DG, Adson AW. Subdural hygroma. Arch Surg 1941;43:559-67.

13 Stone JL, Lang RGR, Sugar O, Moody RA. Traumatic subdural hygroma. Neurosurgery 1981;8:542-50.

14 St. John JN, Dila C. Traumatic subdural hygroma in adults. Neurosurgery 1981;9:621-6.

15 Naganuma H, Fukamachi A, Kawakami M, Misumi S,
Nakajima H, Wakao T. Spontaneous resolution of chronic subdural hematomas. Neurosurgery 1986;19: 794-8.

16 Ohno K, Suzuki R, Masaoka H, Matsushima Y, Inaba Y, Monma S. Role of traumatic subdural fluid collection in developing process of chronic subdural hematoma. Bull Tokyo Med Dent Univ 1986;33: 99-106. 